\title{
Guest-responsive structural adaptation of a rationally-designed molecular tweezer based on Tröger's base
}

\author{
ISHITA NEOGI, ALANKRITI BAJPAI and JARUGU NARASIMHA MOORTHY* \\ Department of Chemistry, Indian Institute of Technology Kanpur, Kanpur 208 016, India \\ e-mail: moorthy@iitk.ac.in
}

MS received 8 May 2014; revised 15 June 2014; accepted 16 June 2014

\begin{abstract}
We have designed and synthesized a modified Tröger's base TB in which the sterically-rigidified aryl rings that protrude into its groove were envisaged to preclude self-inclusion. From a limited preliminary experimentation, TB has been found to exhibit guest inclusion. The X-ray determined structures of the crystals of guest-free TB and its inclusion compounds with acetonitrile and $o$-dichlorobenzene reveal remarkable adaptability of the TB core to undergo subtle structural changes in response to the guest that is included. The structural analyses demonstrate the fact that $\mathbf{T B}$ behaves like a molecular tweezer.
\end{abstract}

Keywords. Tröger’s Base; X-ray Crystallography; Host-Guest Chemistry; Lattice Inclusion.

\section{Introduction}

The knowledge of intermolecular interactions can be beneficially exploited in the design and development of novel crystalline materials with pre-desired properties and functions. This indeed is one of the tenets of crystal engineering. ${ }^{1-3}$ In general, the molecules exhibit a propensity to self-associate and crystallize out. In other words, they are innately programmed to associate with their own kind. Can one then interfere with this natural disposition of molecules and force intermolecular aggregation to create binary, ternary or even higher order multicomponent crystals? While the answer is affirmative, creation of binary or multicomponent crystals with well-defined stoichiometry represents a fundamental challenge in crystal engineering. The knowledge of intermolecular interactions and innovative design of molecular building blocks may allow access to mixed molecular crystals. In this regard, lattice inclusion compounds represent a unique class, which exhibit difficulty for close packing, but do so by incorporation of guest molecules in the crystal lattice. ${ }^{4-8}$ A variety of lattice inclusion compounds based on diverse concepts have been reported in the literature. Incorporation of certain structural attributes in the molecular design can pave way for the development of lattice inclusion hosts in a predictable manner. In our recent investigations, we have shown that sterics can be utilized in the molecular design to develop sterically-rigidified tetraarylpyrenes

*For correspondence characterized by concave features, which exhibit abundant guest inclusion. ${ }^{9-11}$ Based on the same concept, we have further shown that triphenols ${ }^{12,13}$ and triacids ${ }^{14}$ based on benzene/mesitylene core undergo hydrogenbonded aggregation with creation of voids for guest inclusion leading to multicomponent molecular crystals. In continuation of these investigations, our interest was drawn toward the unique V-shape extant to Tröger's bases.

Tröger's bases are $\mathrm{V}$-shaped, chiral, rigid and $\mathrm{C}_{2}$ symmetric molecules, which have been known for long. ${ }^{15-18}$ Due to their unique shape that confers them with inherent deep cavity, the parent Tröger's base and a variety of its derivatives have been explored as host systems for molecular recognition in the solutionstate. ${ }^{19-23}$ The recent literature shows their exploitation as applied to molecular torsional balances, ${ }^{24-26}$ optoelectronics, ${ }^{27-29}$ asymmetric catalysis, ${ }^{30-33}$ etc. So far as the utility of Tröger's bases in the solid state as lattice inclusion hosts is concerned, one finds that the guest inclusion chemistry is surprisingly scant; this indeed is contrary to the expectations based on their structural attributes. ${ }^{34-37}$ A cursory crystal packing analyses of some compounds for which the X-ray crystal structures are deposited in CCDC show at least three different patterns in which the Tröger's bases pack, cf. figure 1; clearly, they exhibit tendency to self-associate in a face-to-face or edge-to-face manner whereby efficient crystal packing is achieved. Herein, we report the design, synthesis and inclusion behaviour of a novel cleft-shaped molecular module $\mathbf{T B}$, vide infra scheme 1, which was designed and synthesized. In TB, 

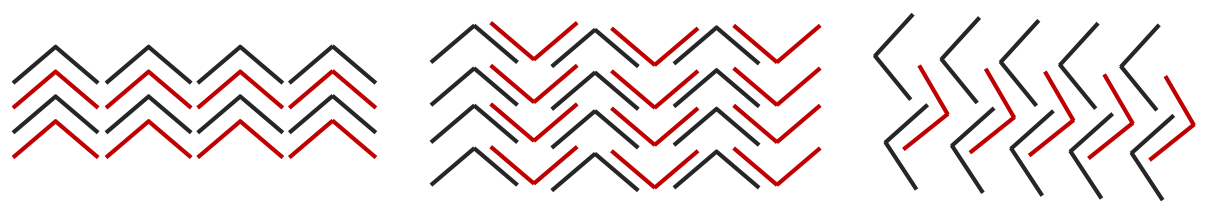

Figure 1. Schematic representation of the modes of self-inclusion of Tröger's base and its derivatives observed in some of the structures deposited in CCDC.

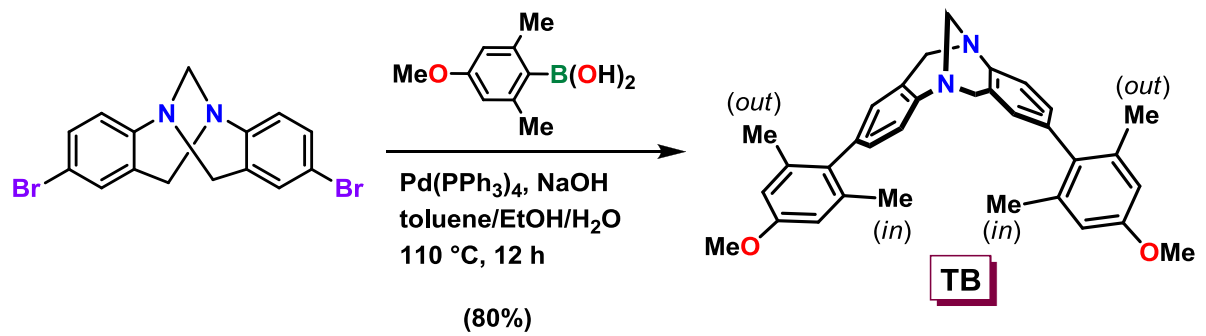

Scheme 1. Synthesis of the host TB.

the aryl substituents are installed orthogonally to the central Tröger's base core by exploiting sterics imposed through the methyl groups. It was surmised that the rigid aryl rings that protrude into the concave region would impede self-inclusion such that close packing may now occur with inclusion of guest species.

\section{Experimental}

\subsection{General aspects}

Column chromatography was conducted with silica gel of 100-200 $\mu$ particle size. NMR spectra were recorded with $400 \mathrm{MHz}$ spectrometers.

\subsection{Procedure for the synthesis of 2,8-bis(2,6-} dimethyl-4-methoxyphenyl)-6H,12H-5,11-methanodibenzo[b.f]diazocine

2,8-Dibromo-substituted Tröger's base was synthesized by following the literature reported procedure. ${ }^{38}$ It was later subjected to $\mathrm{Pd}(0)$-catalyzed Suzuki coupling with 2,6-dimethyl-4-methoxyphenylboronic acid. Thus, an oven-dried two-necked round-bottom flask was charged with dibromo-substituted Tröger's base (1.0 g, $2.63 \mathrm{mmol})$, 2,6-dimethyl-4-methoxyphenylboronic acid (1.9 g, $10.5 \mathrm{mmol}), \mathrm{Pd}\left(\mathrm{PPh}_{3}\right)_{4}(0.6 \mathrm{~g}, 0.52 \mathrm{mmol})$ and $\mathrm{NaOH}(0.6 \mathrm{~g}, 15.8 \mathrm{mmol})$ under $\mathrm{N}_{2}$ atmosphere. The contents were dissolved in a $40 \mathrm{~mL}$ of tolueneEtOH- $\mathrm{H}_{2} \mathrm{O}$ mixture $(3: 2: 1)$ and heated at reflux for 12 h. After completion of the reaction, as monitored by thin-layer chromatography, the contents were evaporated to dryness in vacuo and the residue extracted with
$\mathrm{CHCl}_{3}$ and brine. The organic phase was dried over anhyd. $\mathrm{Na}_{2} \mathrm{SO}_{4}$ and concentrated in vacuo to obtain the crude product. Silica gel column chromatography was performed using $\mathrm{CHCl}_{3}$ /pet. ether $(25 \%)$ as an eluent to obtain pure product as a colourless solid, yield $80 \%$ (1.03 g, $2.10 \mathrm{mmol})$; M.p. $132-136{ }^{\circ} \mathrm{C}$; IR (KBr) cm ${ }^{-1}$ 2949, 2850, 1605, 1477, 1316, 1153, 1073; ${ }^{1} \mathrm{H}$ NMR $\left(\mathrm{CDCl}_{3}, 400 \mathrm{MHz}\right) \delta 1.85$ (s, 3H, Me-in), 2.03 (s, 3H, Me-out), 3.78 (s, 6H), 4.22 (d, $J=16.5 \mathrm{~Hz}, 2 \mathrm{H}), 4.44$ $(\mathrm{s}, 2 \mathrm{H}), 4.75(\mathrm{~d}, J=16.5 \mathrm{~Hz}, 2 \mathrm{H}), 6.6(\mathrm{~d}, J=2.3$ $\mathrm{Hz}, 2 \mathrm{H}), 6.63(\mathrm{~d}, J=2.3 \mathrm{~Hz}, 2 \mathrm{H}), 6.68(\mathrm{~d}, J=1.4$ $\mathrm{Hz}, 2 \mathrm{H}), 6.92$ (dd, $\left.J=8 \mathrm{~Hz}, J_{1}=1.4 \mathrm{~Hz}, 2 \mathrm{H}\right), 7.17$ $(\mathrm{d}, J=7.8 \mathrm{~Hz}, 2 \mathrm{H}) ;{ }^{13} \mathrm{C} \mathrm{NMR}\left(\mathrm{CDCl}_{3}, 400 \mathrm{MHz}\right)$ $\delta 158.3,146.3,137.7,137.6,136.7,134.1,128.9,128$, 127.6, 125.9, 112.63, 112.6, 67.3, 58.9, 55.2. 21.3, 20.9. HRMS $m / z$ calcd for $\mathrm{C}_{33} \mathrm{H}_{35} \mathrm{~N}_{2} \mathrm{O}_{2} 491.2698[\mathrm{M}+\mathrm{H}]^{+}$, found 491.2693.

\section{$2.3 X$-ray crystal structure determinations}

The intensity data for the crystals of TB and its inclusion compounds were collected on a Bruker's SMART CCD. The structure determination and refinement were accomplished with SHELX suite of programs. The hydrogen atoms were generally located from a difference electron density map, and the missing hydrogens were fixed at their geometrically ideal positions. In general, all the non-hydrogen atoms were refined anisotropically, while the hydrogens were treated isotropically. Further, the latter were treated as riding on their nonhydrogen atoms during the refinement. The cifs for all the three structures have been deposited in CCDC and the deposition numbers for TB-A, TB-GF and TB-D are 1001229, 1001230 and 1001231, respectively. 


\section{Results and Discussion}

\subsection{Synthesis of host TB}

The diaryl-substituted Tröger's base was synthesized by $\operatorname{Pd}(0)$-catalyzed 2-fold Suzuki cross coupling reaction between 2,8-dibromo-substituted Tröger's base, i.e., 2,8-dibromo- $6 \mathrm{H}, 12 \mathrm{H}-5,11$-methanodibenzo[b,f][1,5]diazocine and 2,6-dimethyl-4-methoxyphenylboronic acid (scheme 1). The precursor dibromoTröger's base was prepared by following the reported procedure. ${ }^{38}$

\subsection{Lattice inclusion compounds of $\boldsymbol{T B}$ and $X$-ray crystal structure determinations}

Slow evaporation of the solution of $\mathbf{T B}$ in dichloromethane led to crystals of the host in its guest-free form (TB-GF) as revealed by X-ray crystal structure determinations, vide infra. However, the addition of a co-solvent such as acetonitrile and $o$ dichlorobenzene led to isolation of the crystals with inclusion of the co-solvent. The crystals were subjected to X-ray crystal structure determinations to delineate structural features that facilitate or preclude guest inclusion in the solid state. In the following sections we describe the structural aspects of the guest-free Tröger's base (TB-GF) and those containing guest species, namely, acetonitrile (TB-A) and $o$-dichlorobenzene
(TB-D). The crystal data and details of X-ray structure determinations are given in table 1 .

TB-GF. In the absence of any additive, TB crystallized from its solution in DCM without inclusion of any guest. The crystals were found to belong to monoclinic crystal system (space group: $P 2_{1} / \mathrm{n}$ ) with one molecule of $\mathbf{T B}$ in the asymmetric unit cell (figure 2). The crystal packing analysis revealed that the concave surface (endo face) in each TB molecule is occupied by the aryl rings of two adjacent molecules in an endoface to endo-face fashion (figure 2). The crystal packing is characterized by weak van der Waal's interactions involving intertwining of the exo-face to exo-face manner to form layers that propagate along bc-plane down the a-axis (figures 2b). These 2-D layers are in turn found to be stacked along ab-plane down c-axis to make up the crystal.

TB-A. Crystallization of TB in DCM- $\mathrm{CH}_{3} \mathrm{CN}$ solvent combination $(1: 1, \mathrm{v} / \mathrm{v})$ led to thick rectangular crystals belonging to $C 2 / \mathrm{c}$ space group. The structure determination revealed that the asymmetric unit cell contains half molecule of the host TB and acetonitrile. Evidently, both components, that is, TB and acetonitrile, sit on the special positions. The crystal packing analysis reveals that the host accommodates acetonitrile molecule in its concave cavity (endo face) (figure 3a). Analyses of intermolecular interactions show that

Table 1. Crystal data for guest-free TB-GF and its inclusion compounds with acetonitrile and $o$-dichlorobenzene.

\begin{tabular}{|c|c|c|c|}
\hline Compound & TB-GF & TB-A & TB-D \\
\hline Molecular formula & $\mathrm{C}_{66} \mathrm{H}_{68} \mathrm{~N}_{4} \mathrm{O}_{4}$ & $\mathrm{C}_{46} \mathrm{H}_{49} \mathrm{~N}_{4} \mathrm{O}_{2}$ & $\mathrm{C}_{39} \mathrm{H}_{38} \mathrm{Cl}_{2} \mathrm{~N}_{2} \mathrm{O}_{2}$ \\
\hline Formula weight & 981.24 & 708.90 & 637.61 \\
\hline Crystal system & Monoclinic & Monoclinic & Monoclinic \\
\hline Space group & $P 2_{1} /$ n (No. 14$)$ & C2/c (No. 15) & $P 2_{1} /$ n (No. 14) \\
\hline $\mathrm{a}(\AA)$ & $10.462(3)$ & $17.365(1)$ & $10.821(5)$ \\
\hline $\mathrm{b}(\AA)$ & $16.474(3)$ & $17.056(2)$ & $17.446(5)$ \\
\hline$c(\AA)$ & $16.173(4)$ & $10.047(2)$ & $17.219(5)$ \\
\hline$\alpha\left(^{\circ}\right)$ & 90.00 & 90.00 & 90.00 \\
\hline$\beta\left(\left(^{\circ}\right)\right.$ & $105.12(1)$ & $99.97(2)$ & $91.65(2)$ \\
\hline$\gamma\left({ }^{\circ}\right)$ & 90.00 & 90.00 & 90.00 \\
\hline Volume $\left(\AA^{3}\right)$ & $2690.9(11)$ & $2930.9(4)$ & $3249.0(2)$ \\
\hline $\mathrm{Z}$ & 2 & 2 & 4 \\
\hline Calculated density $\left(\mathrm{mg} / \mathrm{m}^{3}\right)$ & 0.973 & 1.205 & 1.303 \\
\hline Absorption coefficient $\left(\mathrm{mm}^{-1}\right)$ & 0.075 & 0.075 & 0.238 \\
\hline $\mathrm{F}(000)$ & 1048 & 1136 & 1344 \\
\hline Goodness-of-fit on $F^{2}$ & 1.002 & 1.012 & 1.013 \\
\hline Final $\mathrm{R}$ indices & $\mathrm{R}_{1}=0.0754$ & $\mathrm{R}_{1}=0.0633$ & $\mathrm{R}_{1}=0.1000$ \\
\hline$[\mathrm{I}>2 \sigma(\mathrm{I})]$ & $\mathrm{wR}_{2}=0.1683$ & $\mathrm{wR}_{2}=0.1378$ & $\mathrm{wR}_{2}=0.2250$ \\
\hline $\mathrm{R}$ indices (all data) & $\mathrm{R}_{1}=0.1662$ & $\mathrm{R}_{1}=0.1219$ & $\mathrm{R}_{1}=0.1865$ \\
\hline & $\mathrm{wR}_{2}=0.2462$ & $\mathrm{wR}_{2}=0.1574$ & $\mathrm{wR}_{2}=0.2669$ \\
\hline
\end{tabular}


(a)

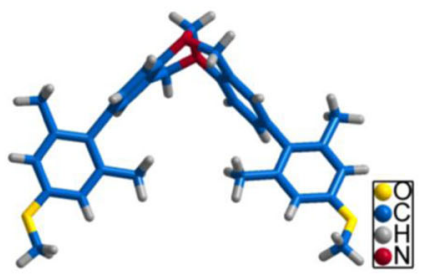

(c)

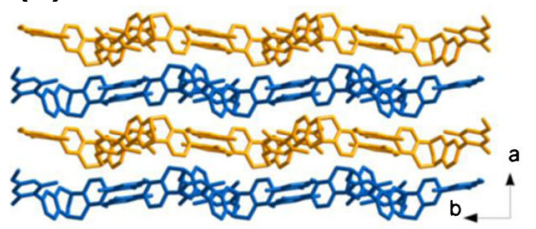

(b)

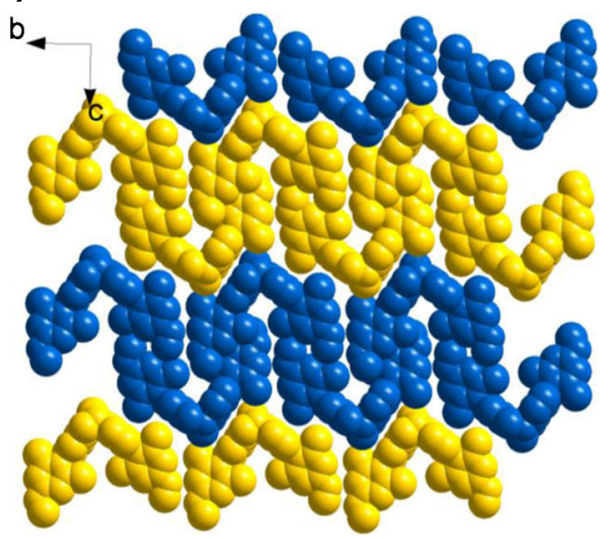

Figure 2. (a) The molecular structure of TB. (b) The overall crystal packing observed in TB-GF showing the association of TB in endo-face to endo-face manner (shown in blue and yellow), which in turn undergo interdigitation to form 2-D layers along bc-plane down c-axis. (c) 2-D layers are found to undergo stacking down a-axis along bc-plane.

$\mathrm{C}-\mathrm{H} \cdots \pi$ interactions $\left(d_{\mathrm{C}-\mathrm{H} \cdots \pi}=2.73 \AA\right.$, $\mathrm{D}_{\mathrm{C} \cdots \pi}=3.59$ $\AA, \theta_{\mathrm{C}-\mathrm{H} \cdots \pi}=147.9^{\circ}$ and $d_{\mathrm{C}-\mathrm{H} \cdots \pi}=2.70 \AA, \mathrm{D}_{\mathrm{C} \cdots \pi}=$ $3.47 \AA, \theta_{\mathrm{C}-\mathrm{H} \cdots \pi}=140.3^{\circ}$ ) operate between the aryl side arms such that the adjacent molecules are offset and partly overlap with each other (figure 3b). The resultant 1-D zigzag chains held by weak interactions were found to run along c-axis. The adjacent chains that run in antiparallel manner are found to face each other in an endoface to endo-face manner. This leads to generation of cavities, which are filled with acetonitrile (figure $3 b$ ). Such 1-D ensembles-two anti-parallel chains accommodating the acetonitrile guests - undergo interdigitation via exo-face to exo-face alignment to form 2-D layers in the bc-plane, which stack down a-axis giving rise to the overall crystal structure (figure $3 \mathrm{c}$ ).

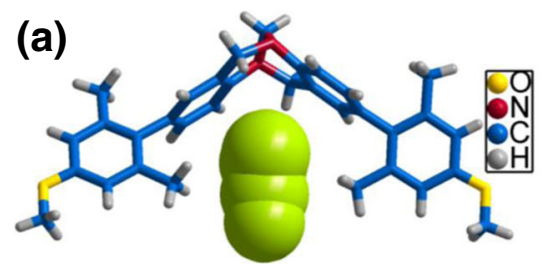

(c)

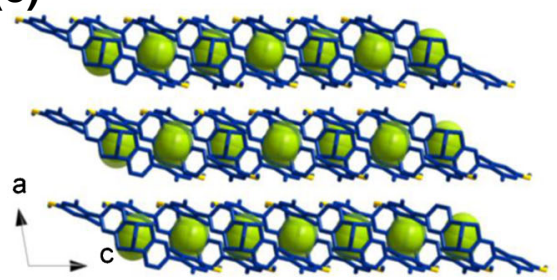

TB-D. Crystallization of TB in dichloromethane in the presence of $o$-dichlorobenzene led to thick needles of the inclusion compound (TB-D). The crystals were found to belong to monoclinic crystal system with $P 2_{1} / \mathrm{n}$ space group. The asymmetric unit cell was found to contain one molecule each of $\mathbf{T B}$ and dichlorobenzene. The crystal packing analysis of TB-D revealed that the near orthogonal orientation of the aryl rings with respect to the central Tröger's base derived core permits $\mathrm{C}-\mathrm{H} \cdots \pi$ interactions $\left(d_{C-H \cdots \pi}=2.81 \AA\right.$, $\left.D_{C \cdots \pi}=3.48 \AA, \theta_{C-H \cdots \pi}=127.2^{\circ}\right)$ to be observed between the methyl groups of the host TB and $\pi$ surface of the aromatic guest, i.e., dichlorobenzene. The latter is found to be positioned within the V-shaped cavity (cleft) of the host system (figure $4 \mathrm{a}$ ). Thus, owing

(b)

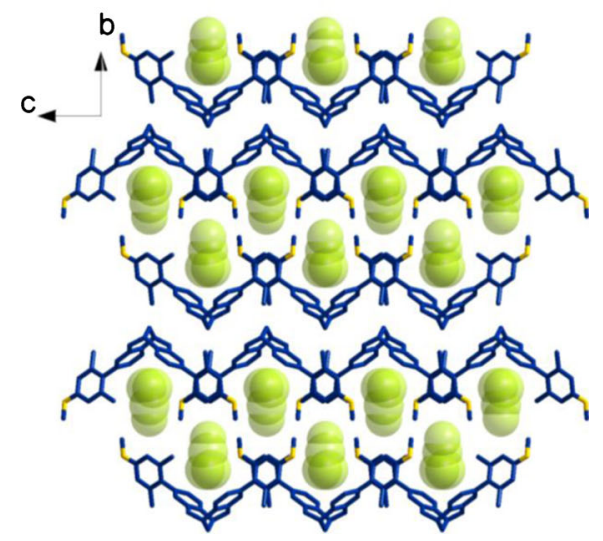

Figure 3. (a) The structure of TB (blue) with the included guest acetonitrile (green). (b) The overall crystal packing of TB-A showing zigzag chains of TB. (c) The 2-D layers in the bc-plane are shown to stack along a-axis. 
(a)

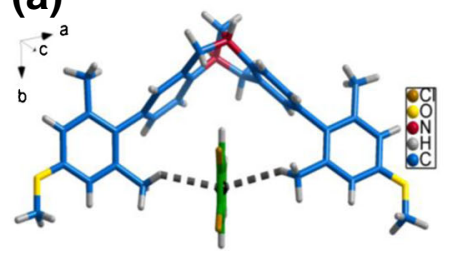

(c)

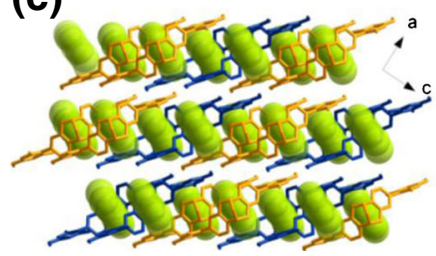

(b)

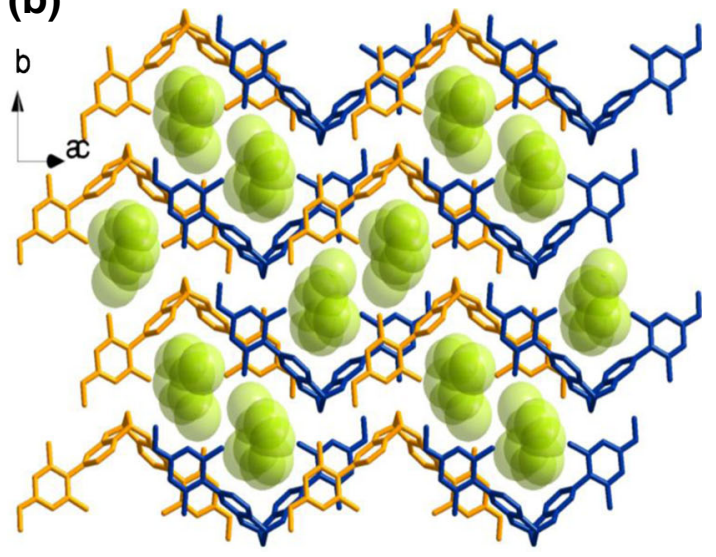

Figure 4. (a) The structure of TB with the guest $o$-dichlorobenzene molecule (green) occupying the concave region (endo face). Notice that the guest is bound via $\mathrm{C}-\mathrm{H} \cdots \pi$ interactions. (b) The crystal packing diagram for TB-D depicting the anti-parallel disposition of the two adjacent host TB molecules (shown in blue and yellow). (c) The 2-D layers in ac-plane that stack.

to its inherent structural feature, host $\mathbf{T B}$ can be considered as a molecular tweezers that 'picks' aromatic guests like dichlorobenzene thereby preventing selfinclusion. Unlike in case of TB-A, the adjacent TB molecules in each 1-D zigzag chain, which are held together by weak $\mathrm{C}-\mathrm{H} \cdots \pi$ interactions, were found to lie anti-parallel to each other (figure 4). Such 1-D chains are seen to pack one on top of the other into a 2-D layer in the ab-plane down c-axis. These layers are, in turn, found to stack along ac-plane thereby forming channels filled with $o$-dichlorobenzene molecules (figure $4 \mathrm{c}$ ).

\subsection{Guest-responsive structural expansion}

As mentioned at the outset, Tröger's bases are endowed inherently with a groove for guest inclusion. However, the lattice inclusion of guests within the groove is subverted by their propensity to undergo self inclusion. Our premise was to obviate this tendency and engineer guest inclusion in a manner that the modified Tröger's bases may function as molecular tweezers. Thus, we installed 2,6-dimethyl- $p$-anisyl rings at the para positions of the $C_{2}$-symmetric Tröger's base to render the former to protrude into the groove of the V-shaped Tröger's base due to orthogonality ensured by sterics. In other words, the aryl rings were deemed to act as 'stoppers' to restrict the self-inclusion of TB molecules. Crystallization of the host TB in dichloromethane led to guest-free crystals in which the TB host molecules are found to pack with endo-face of one interacting with the endo-face of the neighbour such that the overall crystal packing is loose; the crystal packing (spacefilling model) reveals significant void volumes in the lattice (figure 2). However, crystallization of TB in the presence of acetonitrile and $o$-dichlorobenzene led to crystals including these guests. A closer inspection of molecular structure of TB in its various crystal forms, namely TB-GF, TB-A and TB-D, reveals remarkable changes in the Tröger's base scaffold. As shown in figure 5, one finds that the internal groove is closed up in

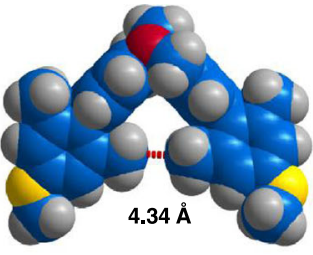

TB-GF

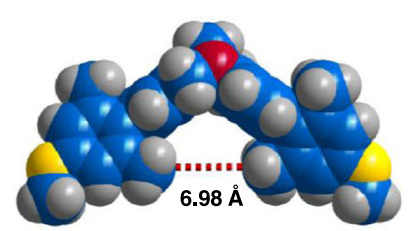

TB-A

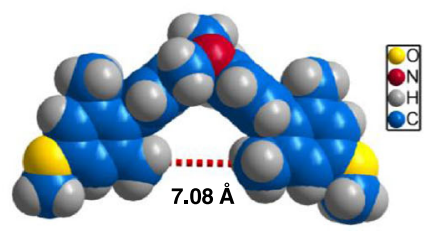

TB-D

Figure 5. The space-filling structures of TB as observed in its guest-free state (left) and its lattice inclusion compounds formed with acetonitrile (centre) and dichlorobenzene (right). Observe the tweezer-like behaviour of TB in its lattice inclusion compounds with acetonitrile and $o$-dichlorobenzene, wherein the distance between the two carbons of the methyl groups that project into the hydrophobic groove increases when the guest molecules are bound. 
Table 2. Some structural parameters for the TB in the crystal structures determined.

\begin{tabular}{llll}
\hline Structural parameters & TB-GF & TB-A & TB-D \\
\hline $\begin{array}{l}\text { Interplanar angle between the aryl } \\
\text { moieties of the TB core }\left(^{\circ}\right)\end{array}$ & 87.33 & 70.76 & 77.14 \\
$\begin{array}{c}\text { Interplanar angle }(\mathrm{s}) \text { between the } \\
\text { aryl rings and the TB core }\left(^{\circ}\right)\end{array}$ & 77.85 & 78.40 & 73.53 \\
$\mathrm{C}(\mathrm{Me}) \cdots \mathrm{C}(\mathrm{Me})$ distance $(\AA)$ & 4.55 & & 69.27 \\
\hline
\end{tabular}

the case of guest-free structure, i.e., TB-GF. However, in the acetonitrile and dichlorobenzene structures, the groove in the scaffold is found to be widened to facilitate guest inclusion. Some of the geometrical parameters calculated for the Tröger's base core in all the three structures determined are collected in table 2 . The striking parameter is the distance between the carbons of methyl groups that project into the groove region of TB. While this distance, i.e., $\mathrm{C}(\mathrm{Me}) \cdots \mathrm{C}(\mathrm{Me})$ is $4.34 \AA$ in TB-GF, it increases to $7.08 \AA$ in TB-D. In concomitant with these changes, one finds that 2,6dimethyl- $p$-anisyl rings exhibit little flexibility in terms of their near orthogonality with respect to the arene moieties of the $\mathbf{T B}$ core; while the interplanar angles between the arene moieties of $\mathbf{T B}$ and $p$-anisyl rings are $69-74^{\circ}$ in TB-D, they are ca. $79-80^{\circ}$ for TB-GF and TB-D. As the $\mathrm{C}(\mathrm{Me}) \cdots \mathrm{C}(\mathrm{Me})$ distance is controlled by a combination of i) angle between the aryl moieties of the $\mathbf{T B}$ core and ii) interplanar angle between the aryl rings and the $\mathbf{T B}$ core, one does not observe a ready correlation of the distance with any one of the two angles. A remarkable guest-dependent change in the core skeleton is also reflected form the angles between the arene moieties of the TB core. As given in table 1, the angle between the arene moieties of $\mathbf{T B}$ vary from ca. $71^{\circ}$ in $\mathbf{T B}-A$ to $77^{\circ}$ in $\mathbf{T B}-\mathrm{D}$ to $87^{\circ}$ in $\mathbf{T B}$ GF. Clearly, the adaptability of the host $\mathbf{T B}$ in response to the guest via subtle structural changes through variation in the angles between the arene planes of the TB core and the interplanar angles between the aryl rings and the arene moieties themselves is compellingly evident.

Figure 6 shows overall packing modes observed for TB-GF, TB-A and TB-D. As mentioned earlier, the crystal packing is loose in TB-GF $\left(d=0.95 \mathrm{~g} / \mathrm{cm}^{3}\right)$, while it gets better and better with inclusion of guests ( $d=0.97$ and $1.16 \mathrm{~g} / \mathrm{cm}^{3}$ for TB-A and TB-D). Otherwise, the limited number of crystal structures compellingly bring out the fact that host $\mathbf{T B}$ effectively behaves like a 'tweezer' in binding suitable guests by adapting itself into geometries that are best complementary to the guests. In the case of TB-A, the limited space within the endo-face of $\mathbf{T B}$ serves as a passive cavity for small and linear molecules such as acetonitrile whereby lattice stabilization is achieved by close packing. Furthermore, two methyl groups that project toward the endo-face bind the aromatic molecules, e.g., $o$-dichlorobenzene, by multiple $\mathrm{C}-\mathrm{H} \cdots \pi$ interactions (TB-D). Thus, we have shown that the guest inclusion can be engineered by exploitation of sterics in the design of modified Tröger's base that is $\mathbf{T B}$, which exhibits inclusion behaviour as demonstrated by the structures of TB-A and TB-D.

\section{Conclusions}

Tröger's base is a unique V-shaped molecular system with inherent capability for guest inclusion. Incidentally, the guest inclusion in the solid state is limited by its self-inclusion. Based on a rational design, we have shown from limited structural investigations that the diarylated Tröger's base TB exhibits guest inclusion. The X-ray determined structures of the guest-free crystals and those of the inclusion compounds formed with acetonitrile and dichlorobenzene reveal remarkable ability of the host TB to undergo subtle structural changes and adapt geometries that are complementary to the guests. TB is found to function effectively like a molecular tweezer.

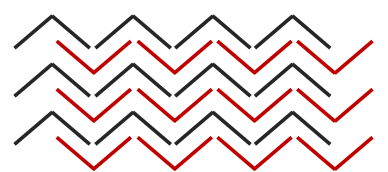

TB-GF

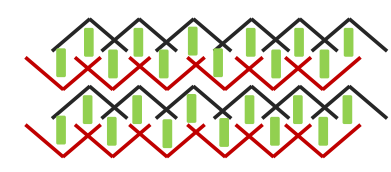

TB-A

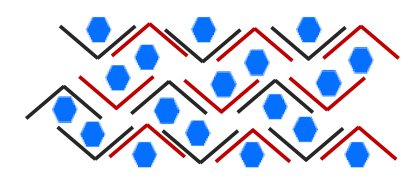

TB-D

Figure 6. Schematic drawing showing the packing modes of host TB in the crystal structures examined in the present study. 


\section{Supplementary Information}

The ${ }^{1} \mathrm{H}$ NMR spectra of the crystals of the inclusion compounds in $\mathrm{CDCl}_{3}$ and TGA profiles. The electronic supporting information can be seen at www.ias.ac.in/ chemsci.

\section{Acknowledgements}

JNM is thankful to SERB (DST) for generous financial support. IN and $\mathrm{AB}$ are grateful to CSIR for their senior research fellowships.

\section{References}

1. Desiraju G R 1989 In Crystal engineering: The design of organic solids (Amsterdam: Elsevier)

2. D Braga and A G Orpan 1999 In Crystal engineering: From molecules and crystals to materials NATO ASI Series (The Netherlands: Kluwer)

3. Desiraju G R 2007 Angew. Chem. Int. Ed. 468342

4. MacNicol D D 1994 In Inclusion compounds (London: Academic Press)

5. Weber E 1996 In Shape and symmetry in the design of new hosts, in Comprehensive Supramolecular Chemistry, Vol. 6, Solid State Supramolecular Chemistry: Crystal Engineering D D MacNicol, E Toda and R Bishop (Eds.) (Oxford: Pregamon) p 535

6. Bishop R 2012 Synthetic clathrate systems, in Supramolecular chemistry: From molecules to nanomaterial (Chichester: Wiley) p 3033

7. Bishop R 2012 Aust. J. Chem. 651361

8. Bishop R 1996 Chem. Soc. Rev. 311

9. Moorthy J N, Natarajan P and Venugopalan P $2009 \mathrm{~J}$. Org. Chem. 748566

10. Natarajan P, Bajpai A, Venugopalan P and Moorthy J N 2012 Cryst. Growth Des. 126134

11. Bajpai A, Natarajan P, Venugopalan P and Moorthy J N 2012 J. Org. Chem. 777858

12. Moorthy J N and Natarajan P 2010 Chem. Eur. J. 16 7796

13. Moorthy J N, Natarajan P, Bajpai A and Venugopalan P 2011 Cryst. Growth Des. 113406

14. Bajpai A, Venugopalan P and Moorthy J N 2013 Cryst. Growth Des. 134721
15. Tröger J 1887 J. Prakt. Chem. 36225

16. Bag B G 1995 Curr. Sci. 68279

17. Thierry M, Pardo C and Elguero J 2005 Helv. Chim. Acta $\mathbf{8 8} 1199$

18. Rúnarsson O V, Artacho J and Wärnmark K 2012 Eur. J. Org. Chem. 7015

19. Cowart M D, Sucholeiki I, Bukownik R R and Wilcox C S 1988 J. Am. Chem. Soc. 1106204

20. Adrian J C and Wilcox C S 1989 J. Am. Chem. Soc. 111 8055

21. Adrian J C and Wilcox C S 1991 J. Am. Chem. Soc. 113 678

22. Goswami S and Ghosh K 1997 Tetrahedron Lett. 38 4503

23. Hansson A P, Norrby P-O and Wärnmark K 1998 Tetrahedron Lett. 394565

24. Paliwal S, Geib S and Wilcox C S 1994 J. Am. Chem. Soc. 1164497

25. Kim E-I, Paliwal S and Wilcox C S 1998 J. Am. Chem. Soc. 12011192

26. Bhayana B and Wilcox C S 2007 Angew. Chem. Int. Ed. 466833

27. Xin Q, Tao X-T, Wang F-Z, Sun J-L, Zou D-C, Wang F-J, Liu H-J, Liu Z, Ren Y and Jiang M-H 2008 Org. Electron. 91076

28. Sergeyev S, Didier D, Boitsov V, Teshome A, Asselberghs I, Clays K, Velde C M L V, Plaquet A and Champagne B 2010 Chem. Eur. J. 168181

29. Xue Y C, Qian X, Jun L H, Lei W, Hua J M and Tang T X 2011 Sci. China Chem. 54587

30. Minder B, Schürch M, Mallat T and Baiker A 1995 Catal. Lett. 31143

31. Xu F, Tillyer R D, Tschaen D M, Grabowski E J J and Reider P J 1998 Tetrahedron Asymmetry 91651

32. Shen Y-M, Zhao M-X, Xu J and Shi Y 2006 Angew. Chem. Int. Ed. 458005

33. Wu H, Chen X- M, Wan Y, Ye L, Xin H-Q, Xu H-H, Yue C-H, Pang L-L, Ma R and Shi D-Q 2009 Tetrahedron Lett. 501062

34. Weber E, Müller U, Worsch D, Vögtle F, Will G and Kirfel A 1985 Chem. Commun. 1578

35. Xin Q, Tao X-T, Liu H-J, Ren Y and Jiang M-H 2008 Cryst. Eng. Comm. 101204

36. Solano C, Svensson D, Olomi J, Jensen J, Wendt O F and Wärnmark K 2005 Eur. J. Org. Chem. 3510

37. Yuan C-X, Tao X-T, Ren Y, Li Y, Yang J-X, Yu, T-W, Wang L and Jiang M-H 2007 J. Phy. Chem. C 11112811

38. Jensen J, Strozyk M and Wärnmark K 2003 J. Heterocyclic Chem. $\mathbf{4 0} 373$ 